\title{
Alternative life-histories in a socially polymorphic ant
}

\author{
Hervé Rosset · Michel Chapuisat
}

Received: 28 June 2006/ Accepted: 26 October 2006/Published online: 30 November 2006

(C) Springer Science+Business Media B.V. 2006

\begin{abstract}
Social organisms vary greatly in the number of breeders per group; yet, the causes and consequences of this variation remain poorly known. Here, we show that variation in social structure is tightly linked with changes in several fundamental life-history traits within one population of ants. Multiple-queen colonies of Formica selysi were much more populous than single-queen ones. They also occurred in areas of higher nest density, had longer colony lifespan, produced smaller queens that presumably disperse less, and invested less in reproductive individuals relative to workers. These multiple changes in life histories are consistent with a shift in the mode of colony foundation and the degree of philopatry of queens. They may also provide various fitness benefits to members of multiple-queen colonies and are likely to play a central role in the evolution and maintenance of polymorphic social structures.
\end{abstract}

Keywords Social evolution · Queen number · Colony size $\cdot$ Lifespan · Reproductive investment $\cdot$ Formica selysi

\section{Introduction}

The emergence of complex societies is one of the most fascinating outcomes of organic evolution. It also constitutes one of the few major evolutionary transitions of life on earth (Szathmary and Maynard Smith 1995). When a major transition occurs, autonomous units loose their independence to become part of a larger whole that forms a new target of selection. Co-operatively breeding birds and mammals represent the beginning of such a transition, with the emergence of non-reproductive helpers that usually retain the possibility of later reproduction (Emlen 1997). Insect societies are further integrated, with some individuals typically monopolizing

H. Rosset · M. Chapuisat $(\square)$

Department of Ecology and Evolution, Biophore, University of Lausanne,

1015 Lausanne, Switzerland

e-mail: michel.chapuisat@unil.ch 
reproduction whereas other individuals become permanently non-reproductive workers (Wilson 1971).

To date, kin selection is the leading explanation for the evolution of reproductive altruism and persistence of worker sterility in insect societies (Hamilton 1964; Keller and Chapuisat 1999; Foster et al. 2006). Basically, workers helping to rear relatives indirectly transmit copies of their own genes to the next generation, and thus increase their inclusive fitness (Hamilton 1964). The net outcome depends on the genetic relatedness among the group members, as well as on the ecological benefits and costs of co-operation.

A surprising aspect of social insect biology is that colonies are often composed of multiple families. In ants, the number of queens per colony is a particularly labile trait that varies among species, among populations and even among colonies within the same population (Bourke and Franks 1995; Crozier and Pamilo 1996; Ross 2001; Chapuisat et al. 2004). Polygyny (the stable coexistence of multiple reproducing queens in the same colony) is common and widespread, occurring in approximately half of the European species (Keller 1993). However, the evolution of multiplequeen colonies seems paradoxical as the presence of multiple breeders reduces the relatedness among colony members, which decreases both the inclusive fitness of workers and the per capita reproductive output of queens (Bourke and Franks 1995; Keller 1995; Crozier and Pamilo 1996).

The large amount of variation in colony social structure suggests that selective pressures vary in space and time, with the presence of multiple families in the same colony being positively selected in some particular ecological conditions (Keller 1993; Bourke and Franks 1995; Hölldobler and Wilson 1977). The question is akin to the factors influencing family dynamics and the partitioning of reproduction in co-operatively breeding birds and mammals (Emlen 1997). Ecological constraints limiting the independent breeding are likely to play a major role in promoting the evolution of extended families in both the vertebrates and the invertebrates. However, the impact of ecological constraints will largely depend on the particular biology and life-history of a species (Pen and Weissing 2000; Hardling and Kokko 2003).

In ants, the shift from single- to multiple-queen colonies is generally associated with variation not only in the genetic composition of the colony, but also in multiple interconnected behavioural and life-history traits that have been collectively referred to as the polygyny syndrome (Keller 1993; Bourke and Franks 1995; Hölldobler and Wilson 1977). This polygyny syndrome links the presence of multiple queens with profound changes in demography, dispersal and mode of colony founding (Bourke and Franks 1995; Ross and Keller 1995). Specifically, queens produced by single-queen colonies usually participate in mating flights and disperse far away from their natal nest to found new colonies independently. In contrast, queens from multiple-queen colonies often mate close to or within their natal nest, where they are often reaccepted. New multiple-queen colonies commonly result from budding, a process whereby a group of mated queens and workers leave their natal colony on foot and establish a new colony in the vicinity (Keller 1993; Bourke and Franks 1995).

Alternatively, multiple queens might also associate to found new colonies after the dispersal flight, a process called pleometrosis (Deslippe and Savolainen 1995; Cahan and Rissing 2005). In most ant genera, these associations of queens are transient, as only one queen survives after the emergence of the first workers 
(Hölldobler and Wilson 1990; Bernasconi and Strassmann 1999). However, pleometrosis results in primary polygyny in a few species (Johnson 2004; D'Ettorre et al. 2005). One way to assess if multiple-queen colonies commonly accept new queens or predominantly result from pleometrosis is to examine the factors that correlate with changes in queen number.

If multiple-queen colonies commonly accept new queens and rarely result from pleometrosis, the differences between single- and multiple-queen colonies in dispersal and mode of colony founding should have a deep impact on a number of interconnected traits. Queens originating from single-queen colonies need large energy reserves to disperse and found new nests without the help of workers. In contrast, queens originating from multiple-queen colonies need fewer reserves if they mate close to the nest and found new nests with the help of workers (Keller and Passera 1989). Queens from polygynous species that accept new queens should also tend to have shorter lifespan, lower fecundity and earlier age of first sexual reproduction (Bourke and Franks 1995; Keller and Genoud 1997).

Variation in queen number and mode of colony founding may also affect the allocation of resources to reproductive individuals versus workers. The general prediction is that multiple-queen colonies that recruit daughter queens and form new colonies by budding should invest more resources in workers and fewer in queens (Crozier and Pamilo 1996). This is because workers help the new queens, and should thus be counted as an investment into females (Pamilo 1990). Moreover, multiplequeen colonies should also invest more in colony maintenance because the colony lifespan exceeds the queen lifespan (Nonacs 1988).

Single- and multiple-queen colonies are indeed predicted to differ markedly in demography and longevity. Because multiple-queen colonies can accept new queens, they are predicted to be very long lasting and might become potentially immortal (Bourke and Franks 1995). In contrast, single-queen colonies will generally only last for the lifespan of their queen, except for very rare cases of queen turnover (Heinze and Keller 2000). The long lifespan of multiple-queen colonies, coupled with high number of reproductive individuals and limited dispersal by budding, can result in very large colonies with numerous individuals and high-nest density (Hölldobler and Wilson 1977).

The genetic consequences of variation in social structure at both the colony and the population levels have been much studied in many ant species (reviewed in Crozier and Pamilo 1996; Pamilo et al. 1997; Ross 2001; Sundström et al. 2005). In contrast, data on the correlated behavioural and life-history traits are rare (Bourke and Franks 1995). Moreover, changes in life-histories have usually been studied by comparing separate populations containing predominantly single- or multiple-queen colonies, respectively (Ross and Keller 1995; Sundström 1995a,b).

The socially polymorphic ant $F$. selysi provides an excellent opportunity to investigate the impact of social structure variation on life-history traits, because single- and multiple-queen colonies occur in close proximity in the same habitat (Chapuisat et al. 2004). The presence of both types of social structure within the same population permits to study life-history correlates of variation in queen number independently of phylogenetic constraints, population idiosyncrasies or variation in ecological conditions. By combining detailed microsatellite information with field data collected over a period of 5 years, we assessed if single- and multiplequeen colonies differed in multiple life-history traits, as predicted by the polygyny syndrome. Specifically, we simultaneously assessed the differences in colony size, 
nest density, colony lifespan, size of queens and males, and investment in reproductive individuals. This approach provides a comprehensive picture of the correlates of social structure variation and thus a better understanding of social evolution in general.

\section{Methods}

\section{Study population}

We studied a population of $F$. selysi situated along the river Rhône between Sierre and Susten in Switzerland (Chapuisat et al. 2004). We placed a flat stone over each focal colony to facilitate subsequent sampling. The study population extends over an area that is approximately $1500-\mathrm{m}$ long and 500-m wide. Focal colonies included in the present study belong to a sample of 112 colonies for which we have detailed data on the social structure, as we have genotyped eight to 100 workers per colony at nine microsatellite markers in 2000, 2001 and 2002 (Chapuisat et al. 2004; Schwander et al. 2005). The life-history data were obtained between 2001 and 2005 as detailed below.

Most $(63 \%)$ of the 112 study colonies are headed by a single queen, whereas the remaining colonies (37\%) have multiple queens, with a genetically effective queen number of 4.3. The genetically effective queen number, estimated as 0.75 divided by the average relatedness among worker nestmates, reflects the number of unrelated and equally reproducing queens that would produce the observed average level of colony relatedness (Ross 2001). This idealized parameter is an underestimate of the actual number of queens if queens are related or share reproduction unequally.

Single- and multiple-queen colonies had similar mating systems, with no inbreeding and no population genetic differentiation above the nest-level (Chapuisat et al. 2004). There was evidence for an ongoing conflict between queens and workers over sex allocation (Trivers and Hare 1976), but single- and multiple-queen colonies did not differ significantly in their sex-investment ratio (Rosset and Chapuisat 2006). Most colonies specialized in the production of a single sex, which was largely determined by the proportion of haploid and diploid eggs laid by the queens (Rosset and Chapuisat 2006).

\section{Colony size, nest density and colony lifespan}

We estimated colony size (number of workers) for 60 single- and 37 multiple-queen colonies with a mark-recapture method, as described in Sundström (1995b). In July and August 2002, we captured workers on the nest surface between 10 and 12 a.m. We marked workers with a small dot of paint on the abdomen. Between 52 and 500 marked workers were returned to their respective colony on the next day, before 10 a.m. Recapture took place by collecting a random sample of workers two days later, between 10 and 12 a.m., on the nest surface. Single- and multiple-queen colonies were sampled in a similar way and in a randomized order. On average, we recaptured $8 \%$ of the marked workers. The number of workers per colony was estimated with the Lincoln index. 
In August and September 2002, we estimated nest density by counting all nest entrances within a $12.5-\mathrm{m}$ radius of the focal colonies (62 single- and 25 multiplequeen ones, respectively). The closest distance between two nest entrances was $80 \mathrm{~cm}$.

The annual mortality of colonies was estimated by monitoring the survival of 107 colonies (70 single- and 37 multiple-queen ones, respectively) over four full years, from 2001 to 2005 . The average colony lifespan was calculated as the inverse of the mean annual mortality rate (Pamilo 1991).

Size of queens and males

We measured the dry weight and body size of winged queens and males just before mating flight. We sampled eight winged males from each of 13 single- and seven multiple-queen colonies, respectively, as well as between one and eight winged queens from 12 single- and 5 multiple-queen colonies, respectively. These individuals were dried for $1 \mathrm{~h}$ at $90{ }^{\circ} \mathrm{C}$ followed by $24 \mathrm{~h}$ at $55^{\circ} \mathrm{C}$, and then weighed to the nearest $0.01 \mathrm{mg}$. In addition, we measured their head width to the nearest $0.001 \mathrm{~mm}$, which is a good estimator of body size (Schwander et al. 2005).

Investment in reproductive individuals

We estimated colony investment in reproductive individuals (new queens and/or males) with a mark-recapture method. The procedure was the same as the one used for adult workers, except for the fact that pupae were collected under the flat stone. All sexual pupae found under the flat stone were marked with a non-toxic pen and returned to the nest. Recapture was made $48 \mathrm{~h}$ later, so that workers had time to mix marked and unmarked pupae. On average, the proportion of marked pupae recaptured was $29 \%$. For each colony-producing queens or males, we performed three to four sessions of mark-recapture between the end of May and mid-June 2001, after larvae had pupated but prior to the first emergence of winged queens and males. We estimated the number of pupae produced by each colony with the Lincoln index, averaging over all mark-recapture sessions (Rosset and Chapuisat 2006). Across the replicates, the mean variation index (standard deviation over mean) for the number of pupae was 0.33 . The overall colony investment in winged queens and males was estimated by summing the number of males and the number of queens multiplied by the queen to male energetic $\operatorname{cost}$ ratio $C$, which corrects for sex-specific cost variation because of differences in fat content and respiration rate $[C=$ (queen dry weight/male dry weight) ${ }^{0.7}$, Boomsma 1989].

\section{Results}

Colony size, nest density and colony lifespan

Multiple-queen colonies were much larger than single-queen ones, with approximately 10 times more workers in the mark-recapture estimates (Fig. 1, Wilcoxon's rank sum test, $Z=6.04, p<0.001)$. The density of nest entrances was also significantly higher around multiple-queen colonies than around single-queen ones (Fig. 2, $t$-test, $t=6.43$, d.f. $=86, p<0.001)$. 
Fig. 1 Colony size (markrecapture estimates of the number of workers) in singlequeen (grey bars) and multiple-queen colonies. Error bars represent $95 \%$ CI. Sample size (number of colonies) is given above the bars

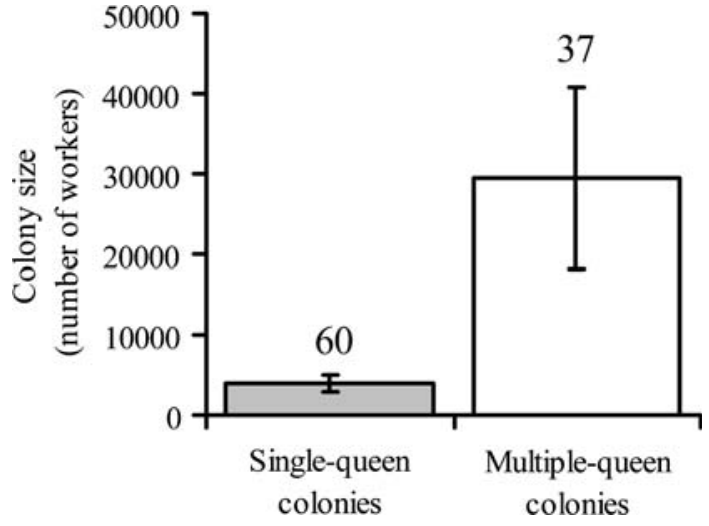

Fig. 2 Nest density (estimated as the number of nest entrances within a $12.5-\mathrm{m}$ radius of the focal colony) around single-queen (grey bars) and multiple-queen colonies. Error bars represent 95\% CI. Sample size (number of colonies) is given above the bars

Fig. 3 Average colony lifespan estimated from colony survival between 2001 and 2005 in single-queen (grey bars) and multiple-queen colonies. Error bars represent 95\% CI. Sample size (number of colonies) is indicated above the bars
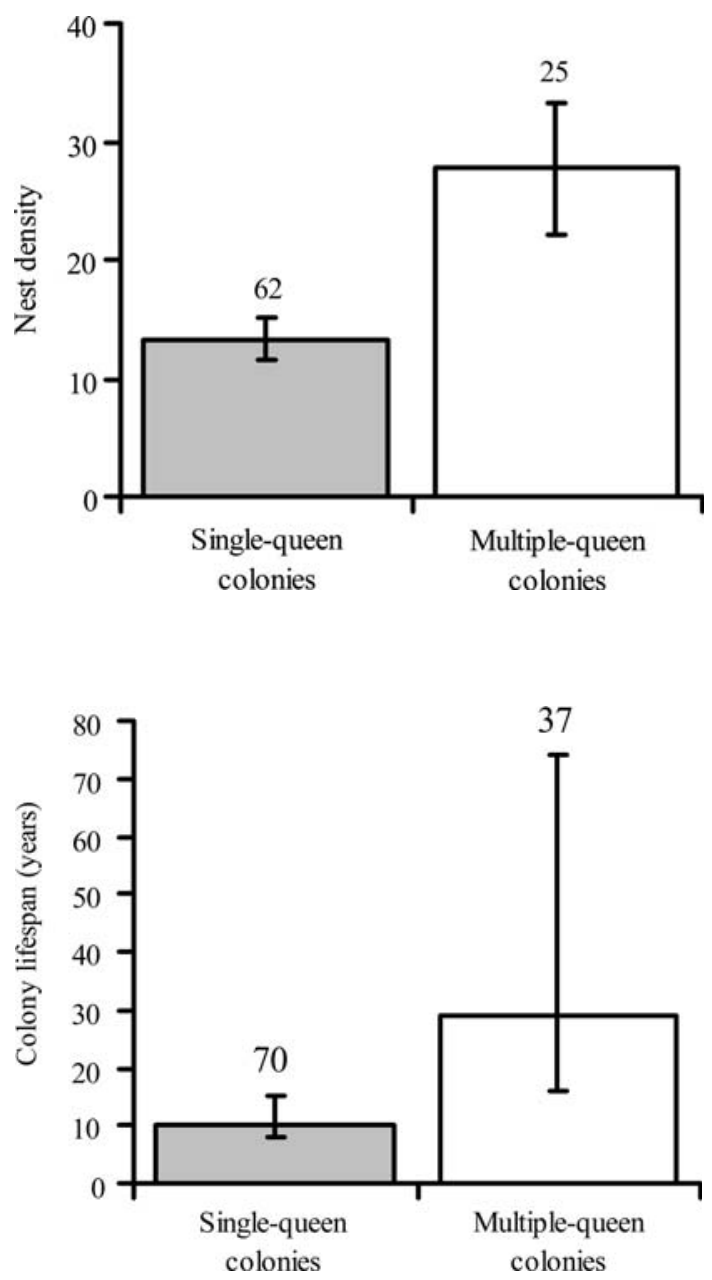
The mortality of single-queen colonies was significantly higher than that of multiple-queen colonies (two-tailed binomial test, $Z=-2.17, p=0.03$ ). Accordingly, the average colony lifespan of multiple-queen colonies was approximately three times longer than that of single-queen colonies (Fig. 3).

Size of queens and males

New queens produced by single-queen colonies were $59 \%$ heavier than queens produced by multiple-queen ones (19.53 mg, 95\% CI 17.2-21.8, vs. $12.28 \mathrm{mg}, 95 \%$

Fig. 4 Amount of energy (estimation expressed in energetic equivalent of one male) invested in queens and males per colony, per worker and per queen in single-queen (grey bars) and multiple-queen colonies. Error bars represent 95\% CI. Sample size (number of colonies) is given above the bars

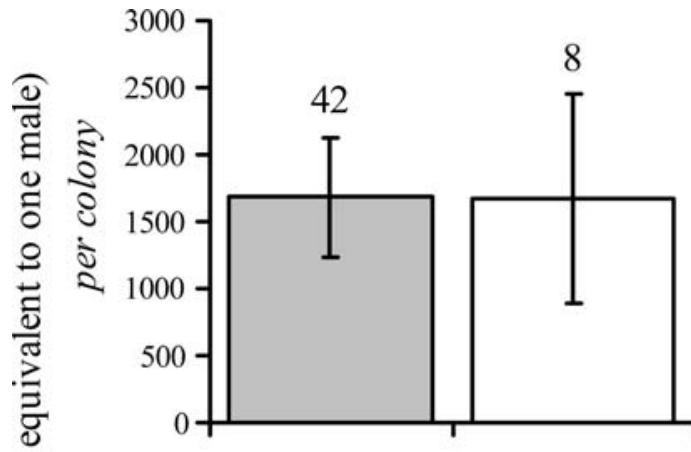

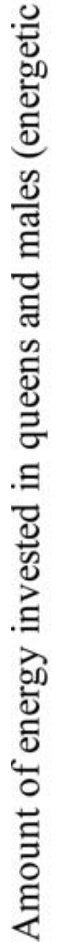
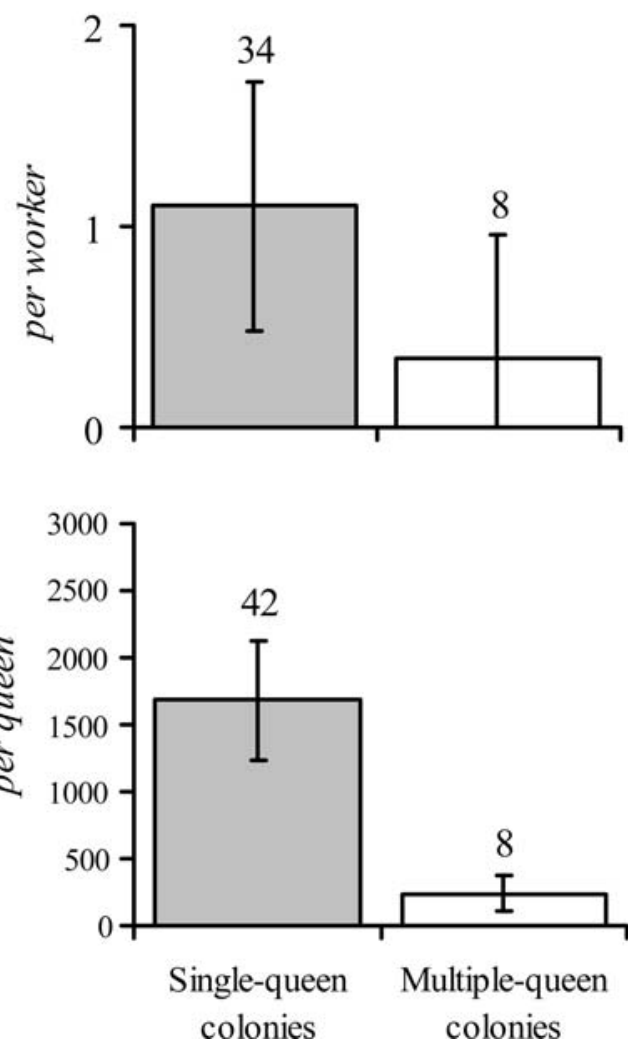

A) Springer 
CI 8.5-16.1, respectively; $t$-test, $t=3.95$, d.f. $=16, p=0.0013)$. The head width of new queens was also slightly larger in single- than in multiple-queen colonies (1.91 mm, 95\% CI 1.89-1.92, vs. 1.87 , 95\% CI 1.83-1.90, respectively; $t$-test, $t=3.05$, d.f. $=16, p=0.008)$. In contrast, no such difference was found for males $(6.35 \mathrm{mg}$, $95 \%$ CI 6.13-6.58, vs. 6.37, 95\% CI 5.98-6.77, respectively; $t$-test, $t=-0.11$, d.f. $=19$, $p=0.91)$.

\section{Investment in reproductive individuals}

When considering only colonies that produced queens or males, the overall amount of energy invested in reproductive individuals was similar in single- and multiple-queen colonies (Fig. 4, Wilcoxon's rank sum test, $Z=-0.54, p=0.59$ ). There was no significant correlation between colony size and reproductive investment within single-queen colonies (Spearman's rank correlation, $n=34$, $Z=-1.23, p=0.22$ ) or multiple-queen ones (Spearman's rank correlation, $n=8$, $Z=-0.60, p=0.55)$.

Because of the larger number of workers in multiple-queen colonies, the per worker investment in reproductive individuals (amount of energy invested in queens and males divided by the number of workers) was approximately three times higher in single- than in multiple-queen colonies (Fig. 4, Wilcoxon's rank sum test, $Z=2.58, p=0.001)$. Similarly, the per queen investment in reproductive individuals (the amount of energy invested in queens and males divided by the genetically effective queen number) was about seven times higher in single- than in multiple-queen colonies (Fig. 4, Wilcoxon's rank sum test, $Z=3.64$, $p=0.0003)$.

When considering all colonies, $27 \%$ of the single-queen colonies produced only workers, on average (Fig. 5). In contrast, 56\% of the multiple-queen colonies produced only workers. This higher proportion of multiple-queen colonies producing only workers was consistent and significant over the five study years (Fig. 5, Fisher's exact tests for each year, $p$-values from 0.0008 to 0.029 ).

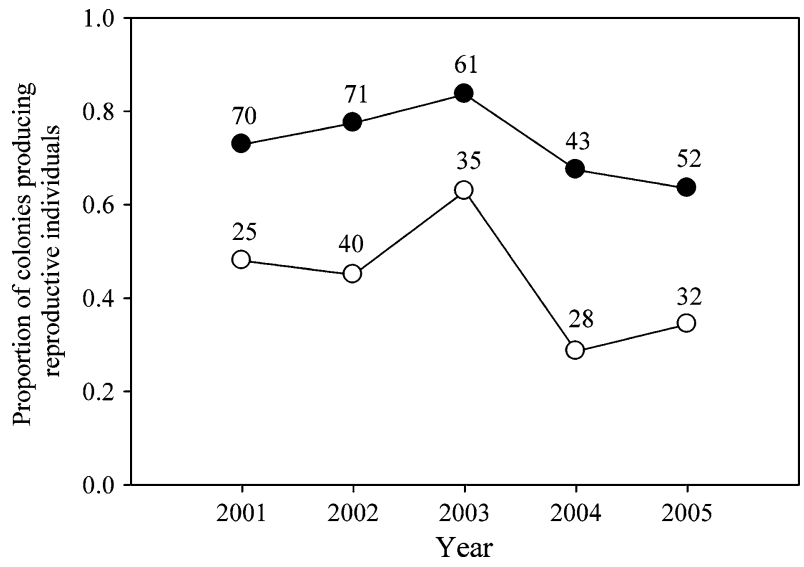

Fig. 5 Proportion of single-queen (black spots) and multiple-queen (white spots) colonies producing reproductive individuals (queens and/or males) over five consecutive years. Sample size (number of colonies) is indicated for each year and social structure

Springer 


\section{Discussion}

Theoretical models suggest that life-histories strongly influence the evolution of social behaviour and partitioning of reproduction in animals (Pen and Weissing 2000; Hardling and Kokko 2003). Reciprocally, sociality will also affect life-history evolution, but detailed empirical data on this covariance are still surprisingly scarce (Bourke and Franks 1995). Here, we show that multiple life-history traits are tightly linked with variation in social structure within one population of ants. The observed differences in life-histories between single- and multiple-queen colonies of $F$. selysi fit remarkably well with the theoretical predictions of the polygyny syndrome. Variation in the number of queens per colony was associated with multiple behavioural and demographic changes that are consistent with a shift in the mode of colony foundation and the degree of philopatry of queens (Hölldobler and Wilson 1977; Keller 1993; Bourke and Franks 1995).

Multiple-queen colonies were much more populous than single-queen ones, as expected from the larger number of breeders and presumably longer colony lifespan. This seems to be a general phenomenon, as a similar trend has been reported in several other ant species (Ross and Keller 1995; Sundström 1995b; Rüppell et al. 1998; Chan et al. 1999; Fournier et al. 2003). However, the difference is particularly pronounced in $F$. selysi, with 10 times more workers in multiple- than in single-queen colonies.

Multiple-queen colonies also occurred in areas of higher nest-density. At the proximate level, this might simply be caused by colony budding, which is restricted to multiple-queen colonies, whereas queens from single-queen colonies disperse further and found new colonies independently. At the ultimate level, it has been hypothesized that all ecological and demographical factors that make solitary colony foundation costly, such as nest site limitation, predation or competition from older colonies, promote the acceptance of additional daughter queens (Bourke and Franks 1995; Keller 1995; Ross and Keller 1995). High population density might thus select for higher queen number and prevalence of colony budding. Data from four ant genera (Formica, Leptothorax, Myrmica and Solenopsis) indeed provide strong support to the hypothesis that queen number increases over time when the habitat becomes saturated (Pamilo and Rosengren 1984; Bourke and Franks 1995; Ross and Keller 1995; Seppä et al. 1995; Pedersen and Boomsma 1999). Interestingly, ecological constraints also play a major role in promoting territory inheritance and co-operative breeding in birds and mammals (Emlen 1997; Pen and Weissing 2000).

We estimated colony lifespan from colony mortality over a period of 4 years and under natural field conditions. The 10-year lifespan of single-queen colonies confirms the remarkable longevity of ant queens (Pamilo 1991; Keller and Genoud 1997). However, it is lower than the mean lifespan of 27 years estimated for F. exsecta (Pamilo 1991). This difference might be explained by the fact that $F$. selysi is a pioneer species that colonizes unstable riverine habitat. Multiple-queen colonies were not immortal, but with a mean lifespan of 29 years they clearly persisted for longer periods of time than single-queen ones, as predicted by the polygyny syndrome.

An interesting result of our study was that queens produced by single-queen colonies were much heavier and slightly larger than those produced by multiple-queen colonies. This difference supports the hypothesis that queens from 
single-queen colonies disperse and found new colonies independently, and thus need large energy reserves, whereas queens from multiple-queen colonies stay in their natal nest and disperse with workers. Such morphological differences are well documented both across and within species (Keller and Passera 1989; Rüppell and Heinze 1999). Hence, the observed queen polymorphism suggests that $F$. selysi queens originating from different colony types differ in dispersal and mode of colony founding. Further experiments are needed to confirm these points. It would also be particularly interesting to investigate experimentally whether the observed queen polymorphism is genetically determined or phenotypically plastic.

In agreement with the idea that queens from multiple-queen colonies found new colonies by budding, multiple-queen colonies invested relatively more resources in workers and less in reproductive individuals. Firstly, the proportion of colonies that produced only workers was significantly larger in multiple- than in single-queen colonies. Secondly, the per capita investment in reproductive individuals was much lower in multiple-queen colonies, for both workers and genetically effective queens. This is a general trend in the social insects (Bourke and Franks 1995; Sundström 1995b). It seems likely that the lower relative investment in reproductive individuals in multiple-queen colonies is balanced by the higher survival of queens founding the new colonies by budding (Nonacs 1993).

Altogether, these results provide considerable indirect evidence for the hypothesis that variation in queen number is associated with a pronounced difference in demography, queen dispersal and mode of colony founding, as predicted by the polygyny syndrome. The fit with the polygyny syndrome at multiple traits (particularly the higher nest density, longer colony lifespan and higher investment in workers in multiple- than in single-queen colonies) suggests that multiple-queen colonies commonly accept new queens and disperse by budding in our study population, whereas pleometrosis seems rare or unlikely to result in permanent polygyny.

So far, the polygyny syndrome had been mostly studied by comparing single traits across populations or species. Our results thus provide an unusually comprehensive view of the multiple facets of the polygyny syndrome. Importantly, queen number variation was correlated with profound changes in colony characteristics within one population and between closely located nests. This suggests that the observed differences in life-histories are tightly associated with shifts in social structure and predate further differences in mating system and population genetic structure (Chapuisat et al. 2004).

The somewhat surprising co-existence of alternative social structures in the same habitat raises the question of the dynamics of the system and fitness of both strategies. The floodplain occupied by $F$. selysi is an unstable habitat that occasionally experiences severe floods, as occurred in 1993 and 2000. It is thus possible that the occurrence of single- and multiple colonies within the same population represents a transitional state, even if the social structure of colonies and the proportion of singleand multiple-queen colonies appeared to be stable over periods of 5-10 years (Chapuisat et al. 2004; this study). Potentially, microgeographical ecological variation might also favour one type of social structure in some areas and the alternative social structure in other areas. For example, diversifying selection might favour polygyny in resource rich patches of habitat and single-queen colonies in less rich areas (Pamilo and Rosengren 1984). 
The multiple changes in life-history traits that are associated with shifts in queen number may provide various fitness benefits to members of multiple-queen colonies. Higher number of workers, longer colony lifespan and dispersal by budding probably confer strong competitive advantages to multiple-queen colonies. Such changes in life-histories are thus likely to play a central role in the evolution of social structures and should be considered along with ecological and genetic factors to get a better understanding of social evolution.

Acknowledgments We thank Samuel Bocherens for help in the field, as well as Serge Aron, Robert L. Hammond, Sara Helms Cahan, Laurent Keller, Pekka Pamilo and two anonymous referees for comments on the manuscript. This study was supported by grants from the Swiss National Science Foundation (number 3100-61934 and 3100-108263).

\section{References}

Bernasconi G, Strassmann JE (1999) Cooperation among unrelated individuals: the ant foundress case. Trends Ecol Evol 14:477-482

Boomsma JJ (1989) Sex-investment ratios in ants: has female bias been systematically overestimated? Am Nat 133:517-532

Bourke AFG, Franks NR (1995) Social evolution in ants. Princeton University Press, Princeton, NJ

Cahan SH, Rissing SW (2005) Variation in queen size across a behavioral transition zone in the ant Messor pergandei. Ins Soc 52:84-88

Chan GL, Hingle A, Bourke AFG (1999) Sex allocation in a facultatively polygynous ant: betweenpopulation and between-colony variation. Behav Ecol 10:409-421

Chapuisat M, Bocherens S, Rosset H (2004) Variable queen number in ant colonies: no impact on queen turnover, inbreeding, and population genetic differentiation in the ant Formica selysi. Evolution 58:1064-1072

Crozier RH, Pamilo P (1996) Evolution of social insect colonies: sex allocation and kin selection. Oxford University Press, Oxford

D'Ettorre P, Kellner K, Delabie JHC, Heinze J (2005) Number of queens in founding associations of the ponerine ant Pachycondyla villosa. Ins Soc 52:327-332

Deslippe RJ, Savolainen R (1995) Colony foundation and polygyny in the ant Formica podzolica. Behav Ecol Sociobiol 37:1-6

Emlen ST (1997) Predicting family dynamics in social vertebrates. In: Krebs JR, Davies NB (eds) Behavioural ecology: an evolutionary approach, 4th edn. Blackwell Science, Oxford, pp 228-253

Foster KR, Wenseleers T, Ratnieks FLW (2006) Kin selection is the key to altruism. Trends Ecol Evol 21:57-60

Fournier D, Keller L, Passera L, Aron S (2003) Colony sex ratios vary with breeding system but not relatedness asymmetry in the facultatively polygynous ant Pheidole pallidula. Evolution 57:1336-1342

Hamilton WD (1964) The genetical evolution of social behaviour. J Theor Biol 7:1-52

Hardling R, Kokko H (2003) Life-history traits as causes or consequences of social behaviour: why do cooperative breeders lay small clutches? Evol Ecol Res 5:691-700

Heinze J, Keller L (2000) Alternative reproductive strategies: a queen perspective in ants. Trends Ecol Evol 15:508-512

Hölldobler B, Wilson EO (1977) The number of queens: an important trait in ant evolution. Naturwissenschaften $64: 8-15$

Hölldobler B, Wilson EO (1990) The ants. Springer-Verlag, Berlin

Johnson RA (2004) Colony founding by pleometrosis in the semiclaustral seed-harvester ant Pogonomyrmex californicus (Hymenoptera : Formicidae). Anim Behav 68:1189-1200

Keller L (1993) Queen number and sociality in insects. Oxford University Press, Oxford, 439 pp

Keller L (1995) Social life: the paradox of multiple-queen colonies. Trends Ecol Evol 10:355-360

Keller L, Chapuisat M (1999) Cooperation among selfish individuals in insect societies. BioScience 49:899-909

Keller L, Genoud M (1997) Extraordinary lifespans in ants: a test of evolutionary theories of ageing. Nature 389:958-960 
Keller L, Passera L (1989) Size and fat content of gynes in relation to the mode of colony founding in ants (Hymenoptera : Formicidae). Oecologia 80:236-240

Nonacs P (1988) Queen number in colonies of social Hymenoptera as a kin-selected adaptation. Evolution 42:566-580

Nonacs P (1993) The effects of polygyny and colony life history on optimal sex investment. In: Keller L (ed) Queen number and sociality in insects. Oxford University Press, Oxford, pp 110-131

Pamilo P (1990) Sex allocation and queen-worker conflict in polygynous ants. Behav Ecol Sociobiol 27:31-36

Pamilo P (1991) Life span of queens in the ant Formica exsecta. Ins Soc 38:111-119

Pamilo P, Gertsch P, Thorén P, Seppä P (1997) Molecular population genetics of social insects. Annu Rev Ecol Syst 28:1-25

Pamilo P, Rosengren R (1984) Evolution of nesting strategies of ants: genetic evidence from different population types of Formica ants. Biol J Linn Soc 21:331-348

Pedersen JS, Boomsma JJ (1999) Effect of habitat saturation on the number and turnover of queens in the polygynous ant, Myrmica sulcinodis. J Evol Biol 12:903-917

Pen I, Weissing FJ (2000) Towards a unified theory of cooperative breeding: the role of ecology and life history re-examined. Proc R Soc Lond B 267:2411-2418

Ross KG (2001) Molecular ecology of social behaviour: analyses of breeding systems and genetic structure. Mol Ecol 10:265-284

Ross KG, Keller L (1995) Ecology and evolution of social organization: insights from fire ants and other highly eusocial insects. Annu Rev Ecol Syst 26:631-656

Rosset H, Chapuisat M (2006) Sex allocation conflict in ants: when the queen rules. Curr Biol $16: 328-331$

Rüppell O, Heinze J (1999) Alternative reproductive tactics in females: the case of size polymorphism in winged ant queens. Ins Soc 46:6-17

Rüppell O, Heinze J, Hölldobler B (1998) Size-dimorphism in the queens of the north American ant Leptothorax rugatulus (Emery). Ins Soc 45:67-77

Schwander T, Rosset H, Chapuisat M (2005) Division of labour and worker size polymorphism in ant colonies: the impact of social and genetic factors. Behav Ecol Sociobiol 59:215-221

Seppä P, Sundström L, Punttila P (1995) Facultative polygyny and habitat succession in boreal ants. Biol J Linn Soc 56:533-551

Sundström L (1995a) Dispersal polymorphism and physiological condition of males and females in the ant Formica truncorum. Behav Ecol 6:132-139

Sundström L (1995b) Sex allocation and colony maintenance in monogyne and polygyne colonies of Formica truncorum (Hymenoptera : Formicidae): the impact of kinship and mating structure. Am Nat 146:182-201

Sundström L, Seppä P, Pamilo P (2005) Genetic population structure and dispersal patterns in Formica ants-a review. Ann Zool Fenn 42:163-177

Szathmary E, Maynard Smith J (1995) The major evolutionary transitions. Nature 374:227-231

Trivers RL, Hare H (1976) Haplodiploidy and the evolution of the social insects. Science 191:249263

Wilson EO (1971) The insect societies. Harvard University Press, Cambridge, MA 